\title{
DETERMINATION OF SOME CHLORINATED ORGANIC POLLUTANTS IN PLANTS AND SOIL SAMPLES FROM KOSOVO
}

\author{
Vlora Gashi $^{1}$, BakirKelmendi ${ }^{2, *}$, NexhdetShala ${ }^{2}$, Ismaij Cacaj ${ }^{2}$, Orinda Gashi ${ }^{3}$ \\ and Valmire Havolli ${ }^{1}$ \\ ${ }^{1}$ Kosovo Institute of Agriculture and Food, Peja, 30000, Kosovo \\ ${ }^{2}$ Faculty of Agribusiness at UNHZ of Peja,30000, Kosovo \\ ${ }^{3}$ UBT Higher Education Institution of Pristina, 10000, Kosovo \\ *E-mail: Bakir.kelmendi@unhz.eu
}

\begin{abstract}
Soil contamination is one of the most important factors influencing the quality of agricultural products. Usage of heavy farm equipment, the land drainage, application of inadequate agrochemicals, emissions from mining, metallurgical, chemical, coal power plants and transport, all generate a number of undesired substances (nitric and sulfur oxides, PAHs, heavy metals, pesticides), which after deposition in soil may influence crop quality.

Thus, the input of these contaminants into the environment should be carefully monitored. This paper presents the data obtained for organ chlorinated pesticides, their residues, PCB and chlorine benzenes in the soil, tomato plants and fruits of agricultural areas.

The samples were taken in March 2014 in the Dukagjini Part, in the village near the Peja and we collect 12 samples. The analysis of the organ chlorinated pesticides was performed by gas chromatography technique using an electron capture detector (GC/ECD). Optima-5 (low/mid polarity, ) capillary column was used for isolation and determination of organ chlorinated pesticides. Interpretation of data was performed using cluster analyze models. Relatively low concentrations of organ chlorinated pesticides and their metabolites were found in the studied samples. Two were the main groups, DDTs and HCHs. The presence of organ chlorinated pesticides residues is probably resulting from their previous uses for agricultural purposes. PCB 52 was the main congener found in soil samples and hexachlorobenzene was the main compound for chlorinated benzene compounds.

Keywords: Organchlorinated Pesticides, PCB, Chlorobenzene, Gas Chromatography, Cluster Analyze
\end{abstract}

(C) RASĀYAN. All rights reserved

\section{INTRODUCTION}

Human exposure to chlorinated organic pollutants primarily occurs through food contamination. Fish, meat, fruit, vegetables, and other dairy products are the most important dietary sources of pesticides and their metabolites for humans. It is widely accepted that these pollutants will be present in food for many years to come. ${ }^{1}$ Great concern was caused by chlorinated compounds, which proved to be extremely persistent in the environment and accumulative in the food chain ${ }^{3,6}$. The application of DDT and many other chlorinated pesticides has been banned in most countries since the $1970 \mathrm{~s}^{4}$. The hopes that it would be possible to clear the environment of the residues of the compound have proved to be futile, despite the passage of time, the monitoring of the environment and food in many countries has confirmed the ubiquity of the compound ${ }^{5}$. The fate of a pesticide applied to soil depends largely on two of its properties: persistence and adsorption. Once applied to cropland, a pesticide may be taken up by plants, adsorbed to plant surfaces, broken down by sunlight or ingested by animals, insects, worms or microorganisms in the soil. It may move downward in the soil and either adhere to soil particles or dissolve in soil water. The pesticide may vaporize and enter the atmosphere (volatilization) or break down via microbial and chemical pathways into less toxic compounds. Pesticides may be leached out of the root zone by rain or

Rasayan J. Chem., 12(3), 1540-1546(2019)

http://dx.doi.org/10.31788/RJC.2019.1235301

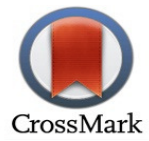


irrigation water or wash off the surface of the land. Properly applied pesticides can reach the surface and underground waters in two ways: in runoff and by leaching. Runoff is the physical transport of pollutants (chemicals or soil) over the ground surface by rainwater, snowmelt or irrigation water that does not penetrate the soil. In the leaching process, pollutants are carried through the soil by rain or irrigation water as it moves downward. Most pesticides in the soil break down or "degrade" over time as a result of several chemical and microbiological reactions. However, some pesticides will continue to degrade by chemical reactions after they have left the root zone. Factors controlling pesticide adsorption include pesticide charge; soil $\mathrm{pH}$, temperature and water content; the presence of previously adsorbed chemicals that have a stronger bond to soil particles; and the amount and type of organic matter present. In general, pesticide adsorption relates inversely to pesticide solubility in water. Highly soluble pesticides are weakly adsorbed and pose a greater threat of groundwater contamination. ${ }^{3}$

\section{EXPERIMENTAL}

A sampling of Tomato Plants, Tomato Fruits and Soil Samples

For this study, we select four villages near Peja/Kosovo, which are the biggest farmers/agricultural areas in Dukagjini Part.The samples were collected in four villages: Qyshke, Leshan, Raushiq and Peja, in a total of 12 samples.

Sampling was performed according to the COMMISSION DIRECTIVE 2002/63/EC ${ }^{7}$, enable to take a representative sample.

\section{Packaging and Transmission}

I labeled and the sampling record I attached to the package which is preserved from contamination, damage, and leakage, I kept the samples cool and immediately I transfer samples to the laboratory.

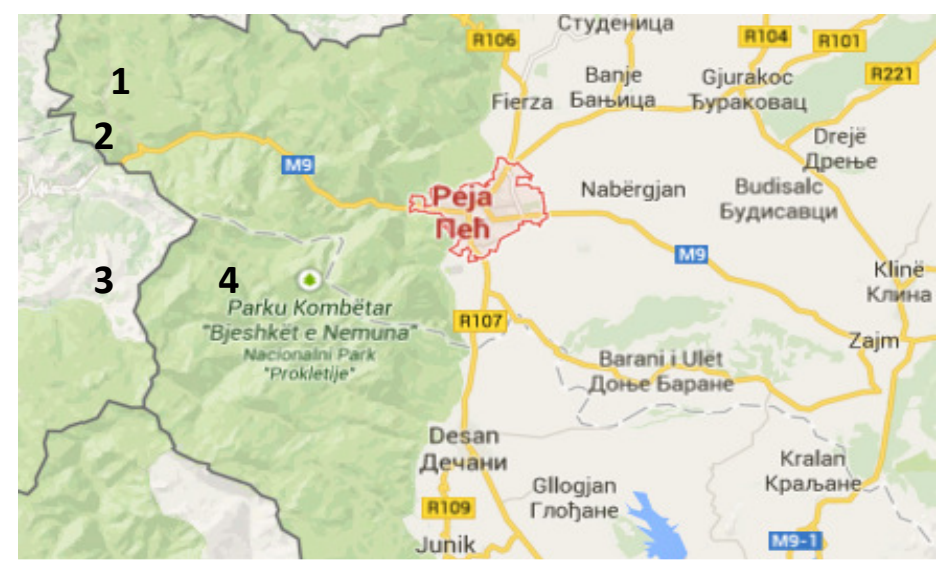

Fig.-1: Map of the Place Where We Collect the Samples

\section{Sample Preparation for Tomato Plants and Tomato Fruits}

We prepare the samples according to the Method $8081 \mathrm{~B}^{8}$. First, we homogenized the samples with the blinder. We weigh $10 \mathrm{~g}$ of sample and transfer the homogenized samples to a clean, tarred, 400- to 500$\mathrm{mL}$ beak, we add $50 \mathrm{ml}$ hexane/dichloromethane 3/1, (v/v) and $5 \mathrm{~g}$ anhydrous sodium sulfate (we put the sodium sulfate in the oven and we dry in $250{ }^{\circ} \mathrm{C}$ over the night), and we extract with ultrasonic bath for $60 \mathrm{~min}$. in $40^{\circ} \mathrm{C}$. The extract was purified with $15 \mathrm{~g}$ silica gel (treated before with $45 \%$ sulfuric acid).

A further clean-up of this extract was performed by using a glass chromatographic column packed with Florisil (Methods 3500) and eluted with $7 \mathrm{ml}$ of hexane/dichloromethane 4/1(v/v). The extract was concentrated to $1 \mathrm{ml}$ in Vials -- Glass, 2 -ml fitted with polytetrafluoroethylene (PTFE)-lined screw caps and analyzed by GC-ECD ${ }^{2}$.

\section{Soil Sample Treatment for GC Analyze}

A fresh sub-sample from $20 \mathrm{~g}$ of soil samples were extracted by ultrasonic bath assisted extraction with $50 \mathrm{ml}$ hexane/dichloromethane 3/1, (v/v). The extract was purified by shaking with 2 gr sodium sulfate 
and $2 \mathrm{~g}$ silica gel, impregnated previously with $45 \%$ sulfuric acid. A further clean-up of this extract was performed in an open glass column packed with Florisil, deactivated with 5\% water. The organ chlorine compounds were eluted with $7 \mathrm{ml}$ of hexane/dichloromethane $4 / 1(\mathrm{v} / \mathrm{v})$. The extract was concentrated to 1 $\mathrm{ml}$ in nitrogen concentrator and after that analyzed by GC-ECD ${ }^{2}$.

\section{Gas Chromatography Analyze}

Gas chromatographic analyses of organ chlorinate pesticides and PCBs were performed with a DANI 1000 gas chromatograph equipped with a ${ }^{63} \mathrm{Ni}$ Electron Capture Detector and a split/split less injector. The column used was an Optima-5 (low/mid polarity, 5\% Phenylmethylsiloxane60 m x $0.33 \mathrm{~mm} \times$ $0.25 \mu \mathrm{m}$ film). The split/splitless injector and detector temperatures were set at $300^{\circ} \mathrm{C}$ and $320^{\circ} \mathrm{C}$, respectively. The carrier gas was helium at $2 \mathrm{ml} / \mathrm{min}$ and make-up gas was nitrogen at $25 \mathrm{ml} / \mathrm{min}$ flow. The initial oven temperature was kept at $60^{\circ} \mathrm{C}$ for 4 minutes than increased to $200^{\circ} \mathrm{C}$ at $20^{\circ} \mathrm{C} / \mathrm{min}$, and then increased to $280^{\circ} \mathrm{C}$ at $40 \mathrm{C} / \mathrm{min}$. The temperature was finally increased to $300^{\circ} \mathrm{C}$, at $10^{\circ} \mathrm{C} / \mathrm{min}$, then held for 7 minutes. Injection volume was $1 \mu \mathrm{l}$ and injections were done in split less mode. Organ chlorine pesticide quantification was performed by an external standard method based in Top Mix 40 standard ${ }^{2}$.

\section{RESULTS AND DISCUSSION}

The upper side of plants, fruits, and soil samples was taken for analyzing for an area of $1 \mathrm{~m}^{2}$. Selected sampling stations were agricultural areas near Peja, Kosovo. Analyze of chlorinated pesticides were performed using GC/ECD technique. Table-1 shows organochloride pesticides data for soil, plant and fruit samples from agricultural areas near Peja, Kosovo.

Figure-2 shown the total concentration of organ chlorinated pesticides in the plant, tomato fruit, and soil samples. The higher levels were found for F1, F2, and P3. It was shown that higher levels were for Fruits $>$ Plant $>$ Soil. This could be because of the metabolism process from soil to plant and after that to fruit. Higher levels in fruit samples could be also because of pesticide treatments from agricultural purposes. These pesticides could be chlorinated pesticides.

Figure-3 shown distributions of organochloride pesticides in all analyzed samples. There was noted the same distribution in all samples. The highest levels were for HCHs, Endrin, Endosulphanes and DDT metabolites.

Figure-4 shown diagram of Cluster Analyze for organochloride pesticides in samples analyzed. It was shown the higher similarities for 1-16 (Teknazencis-Chlordane) with 91.3\%; 19-20 (Dieldrin-DDE) with 89.6\%; 8-26 (e-HCH-Chlordekon) with 87.4\%; 9-25 (Heptachlor-DDT) with 83.3\% and 11-30 (IsodrinMethoxychlor) with $82.1 \%$. It is evident that higher similarities were for the organochloride pesticides used in the past for these areas. Village 1 was the most polluted while Village 4 less polluted for the third type of samples. This could be connected to their geographical position, slope, soil geology, type of crops, water used for irrigation, etc. Figure-4 shown diagram of Cluster Analyze for stations for concentrations found organ chlorinated pesticides. It seems that the levels found in tomato plants P2-P4 with $98.6 \%$ and then $84.3 \%$ P1 were with higher similarities. This may be indicative of bioaccumulation processes to the tomato plant belong to the concentration of pesticides in the soil sample. After that fruit samples showed higher similarities. Soil samples have shown the smaller similarity and the higher difference concern to found data about the pesticides. This is associated with the amount of exposure of these lands by organ chlorine pesticides. Other factors are also geographical position, slope, soil geology, crop type, irrigation water used, etc.

Table-2 shows PCB markers data for soil, plant and fruit samples from agricultural areas near Peja, Kosovo. Figure-5 shown total concentrations of PCBs in the plant, tomato fruit, and soil samples. The higher levels were found for S2, S1 and S3. It was shown that higher levels were for soil samples. This could be because of pollution origin with PCB in these areas. Station 1 was the most polluted while station 4 less polluted for the third type of samples. Figure-6 shown distributions of PCB in all analyzed samples. There was noted the same distribution in all samples. Volatile PCBs were detected and also nonvolatile one. Figure-7 shown diagram of cluster Analyze for PCB markers data in analyzed samples. It was shown the higher similarities for 4-6 (PCB 118 - PCB 138) with 66.4\% after that PCB 28 with 54.3\% similarity and 3-5 (PCB 101-PCB 153) with 64.1\%. This could be connected to their geographical 
RASĀYAN J. Chem.

Vol. 12 | No. 3 |1540 - 1546| July - September | 2019

position, slope, soil geology, water used for irrigation, etc. Figure-8 shown diagram of Cluster Analyze for a place for concentrations found PCB markers. It seems that the levels found in soilS1-P1(village1), S2-S3 (soil samples), F2-F3 (tomato fruit samples), P2-P4 (tomato plant) were with higher similarities. This may be indicative of the same origin of pollution, bioaccumulation processes, geographical position, slope, soil geology, crop type, irrigation water used PCB atmospheric deposition, etc.

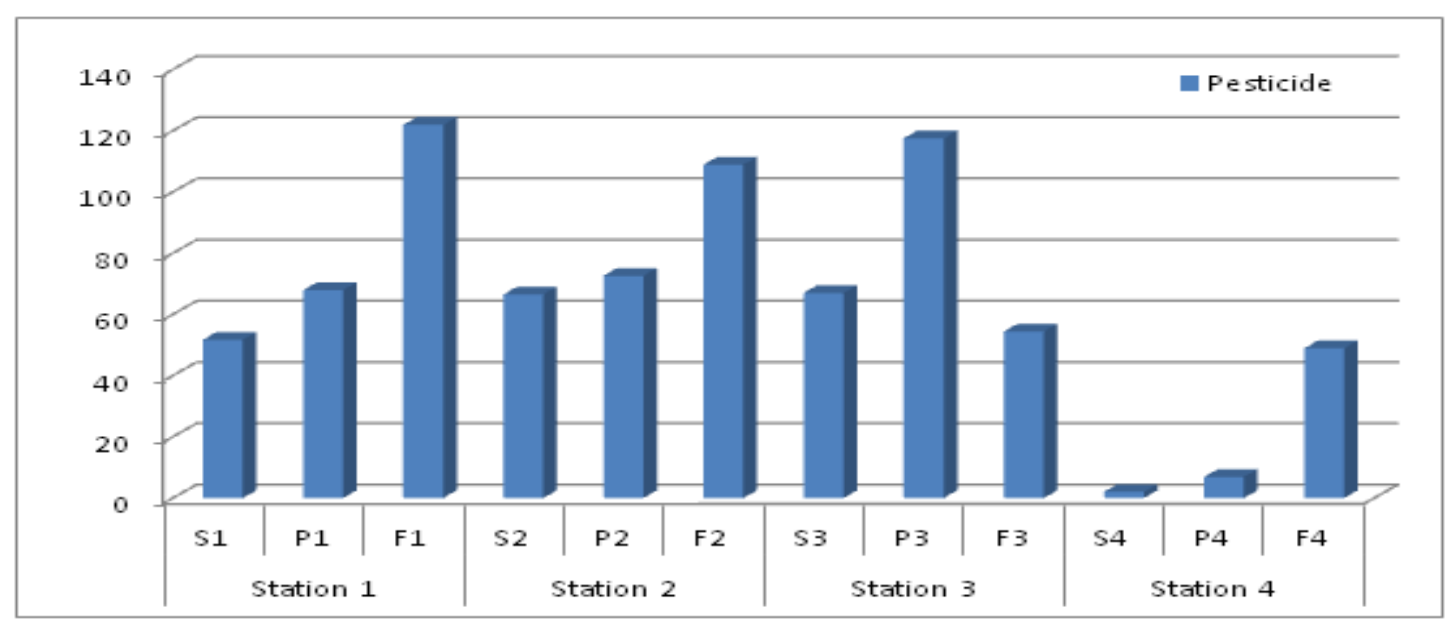

Fig.-2: Total of Organchlorinated Pesticides in Soil, Plant and Tomato Fruit Samples

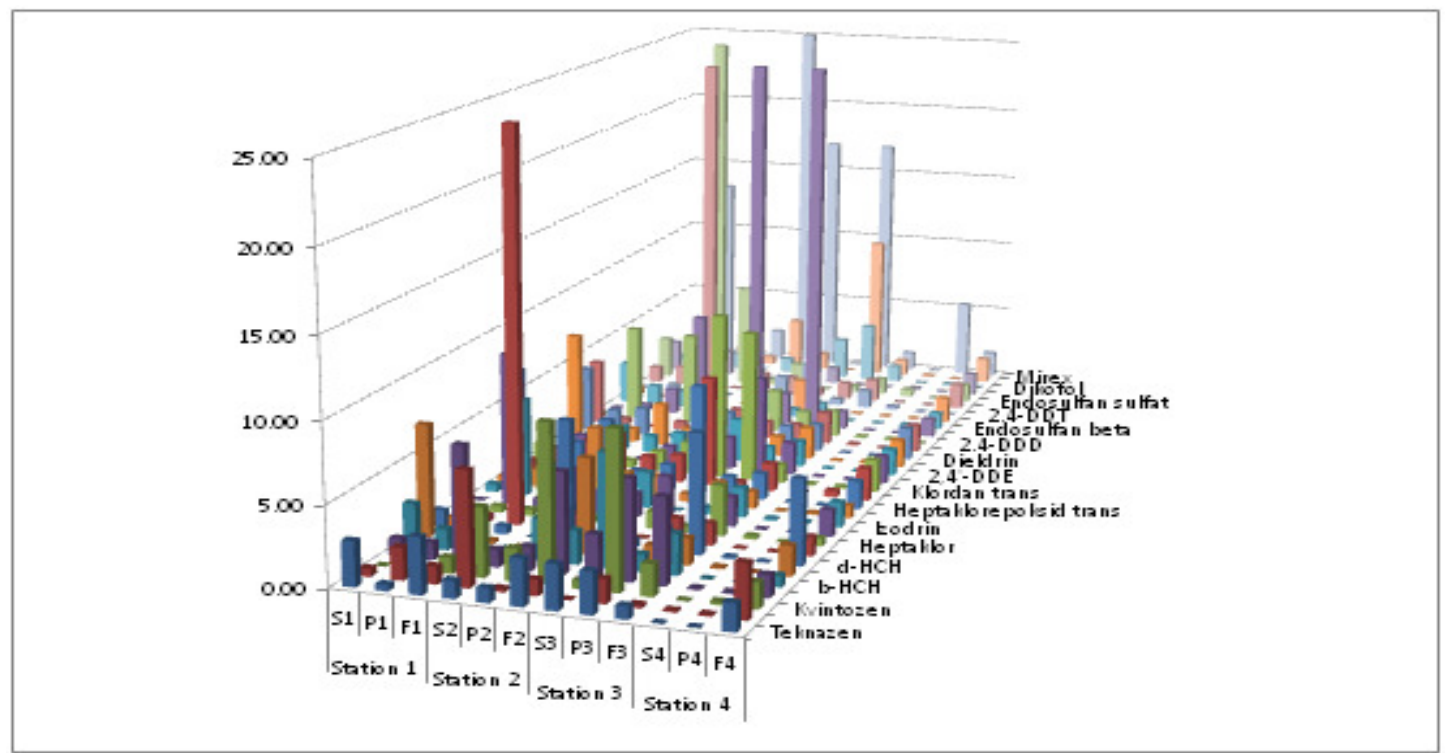

Fig.-3: Distribution of Organ Chlorinated Pesticides in Soil, Plant and Tomato Fruit Samples

Table-1: Organochlorinated Pesticides Data for Soil, Plant and Fruit Samples

\begin{tabular}{l|l|l|l|l|l|l|l|l|l|l|l|l|l}
\hline & & S1 & P1 & F1 & S2 & P2 & F2 & S3 & P3 & F3 & S4 & P4 & F4 \\
\hline & & & & & & & & ppm & & & & & \\
\hline & Tecnazene & 2.82 & 0.40 & 3.50 & 1.10 & 0.91 & 2.90 & 2.82 & 2.60 & 0.80 & n.d & n.d & 1.70 \\
\hline & HCB & 0.55 & 2.00 & 1.10 & 7.10 & 0.20 & 1.00 & 0.00 & 1.50 & 0.20 & 0.10 & 0.10 & 3.50 \\
\hline Quintozene & n.d & 1.50 & 1.00 & 4.30 & 2.00 & 9.50 & 0.50 & 9.80 & 2.00 & n.d & 0.20 & 1.60 \\
\hline & a-HCH & 1.10 & 1.10 & 7.30 & 1.10 & 1.50 & 6.30 & 2.70 & 6.30 & 5.40 & 0.10 & 0.10 & 1.40 \\
\hline b-HCH & 2.70 & 1.30 & 0.62 & 0.50 & 2.60 & 2.10 & 7.10 & 1.10 & 2.60 & n.d & 0.10 & 0.70 \\
\hline & Lindan & 7.10 & 1.50 & 0.20 & n.d & 1.10 & 6.00 & 2.80 & 1.00 & 1.70 & 0.10 & n.d & 1.90 \\
\hline & d-HCH & 1.10 & 1.10 & 0.50 & n.d & 7.60 & 0.70 & 0.50 & 1.50 & 7.60 & 0.10 & n.d & 5.40 \\
\hline & e-HCH & n.d & 0.40 & 28.7 & n.d & 1.10 & 1.20 & n.d & 1.50 & 1.40 & n.d & n.d & 1.20 \\
\hline & Heptachlor & n.d & 0.40 & 0.40 & 0.55 & 0.40 & 1.20 & 1.10 & 0.40 & 3.20 & 0.20 & n.d & 0.50 \\
\hline
\end{tabular}




\section{RASĀYAN J. Chem.}

Vol. 12 | No. 3 |1540 - 1546| July - September | 2019

\begin{tabular}{|c|c|c|c|c|c|c|c|c|c|c|c|c|}
\hline Aldrin & n.d & 9.80 & 0.50 & 2.70 & 1.50 & 1.50 & 2.80 & 1.50 & 1.90 & n.d & n.d & 1.70 \\
\hline Isodrine & 0.50 & 6.30 & 1.10 & 1.10 & 1.30 & 2.32 & n.d & 0.40 & 1.90 & 0.10 & 0.10 & 1.60 \\
\hline $\begin{array}{l}\text { Heptachlor } \\
\text { epoxide cis }\end{array}$ & 0.50 & 1.10 & 0.30 & 4.30 & 1.50 & 1.50 & 0.50 & 1.50 & 1.10 & n.d & 0.10 & 0.80 \\
\hline $\begin{array}{l}\text { Heptachlor } \\
\text { epoxide trans }\end{array}$ & 7.10 & 1.30 & 2.60 & 4.30 & 1.10 & 1.70 & 7.10 & 1.30 & 1.70 & 0.00 & 0.00 & 1.80 \\
\hline Oxychordane & 0.50 & 1.55 & 2.10 & 2.82 & 1.50 & 1.80 & 7.10 & 0.40 & 1.80 & 0.10 & 0.40 & 2.10 \\
\hline Chlordane trans & 1.10 & 1.10 & 1.50 & 0.50 & 1.30 & 2.10 & 10.80 & 9.80 & 1.20 & 0.10 & 0.10 & 2.10 \\
\hline Chlordancis & n.d & 1.32 & 1.70 & n.d & 1.10 & 1.80 & 2.10 & 6.35 & 2.10 & n.d & n.d & 1.80 \\
\hline 2,4'-DDE & 0.50 & 1.10 & 1.60 & 1.10 & 1.50 & 2.10 & 2.80 & 1.10 & 1.70 & n.d & n.d & 1.70 \\
\hline Endosulphanalfa & 7.12 & 0.40 & 0.90 & 2.80 & 1.30 & 1.80 & 0.50 & 1.30 & 2.10 & n.d & 0.10 & 1.80 \\
\hline Dieldrin & 4.30 & 1.50 & 1.82 & n.d & 0.40 & 2.10 & n.d & 1.50 & 1.82 & n.d & n.d & 2.10 \\
\hline 4.4'-DDE & 4.32 & 0.40 & n.d & 0.50 & 1.10 & 1.80 & 1.10 & 1.10 & 2.10 & 0.10 & n.d & 1.80 \\
\hline 2.4-DDD & n.d & 6.40 & n.d & 6.20 & 1.50 & 1.15 & 2.80 & 1.50 & 1.70 & 0.10 & 0.10 & n.d \\
\hline Endrin & n.d & 0.40 & 1.70 & 7.10 & 0.40 & 30.3 & 2.10 & 30.3 & 1.20 & n.d & n.d & 1.20 \\
\hline Endosulphan beta & 2.80 & 1.30 & 1.10 & 2.10 & n.d & 1.50 & n.d & 1.10 & n.d & n.d & 0.10 & 1.10 \\
\hline 4.4-DDD & 0.50 & n.d & n.d & 6.20 & n.d & n.d & 2.10 & n.d & n.d & n.d & n.d & 1.70 \\
\hline 2.4-DDT & n.d & 0.40 & 1.20 & n.d & 1.30 & 1.70 & 2.80 & 0.40 & 1.20 & 0.20 & n.d & n.d \\
\hline Chlordekon & 1.10 & 1.30 & 23.70 & n.d & 1.30 & 1.20 & 0.50 & 1.10 & 1.50 & n.d & n.d & 1.70 \\
\hline Endosulphansulphat & 2.82 & 0.40 & 31.7 & 7.10 & 0.40 & 1.70 & n.d & 0.40 & 1.10 & 0.50 & n.d & 1.20 \\
\hline 4,4 '-DDT & 2.10 & n.d & 1.70 & 0.50 & n.d & n.d & 1.10 & n.d & n.d & 0.10 & n.d & 1.50 \\
\hline Dicofol & 0.50 & 3.00 & 1.10 & n.d & 1.00 & 1.70 & 2.80 & 4.00 & 1.10 & n.d & 0.10 & n.d \\
\hline Methoxychlor & n.d & 6.00 & 1.20 & 0.50 & 3.50 & 1.10 & n.d & 9.90 & 1.10 & 0.10 & n.d & 1.70 \\
\hline Mirex & 0.70 & 13.20 & 1.10 & 2.10 & 32.20 & 16.9 & n.d & 16.90 & 1.20 & 0.00 & 5.30 & 1.70 \\
\hline
\end{tabular}

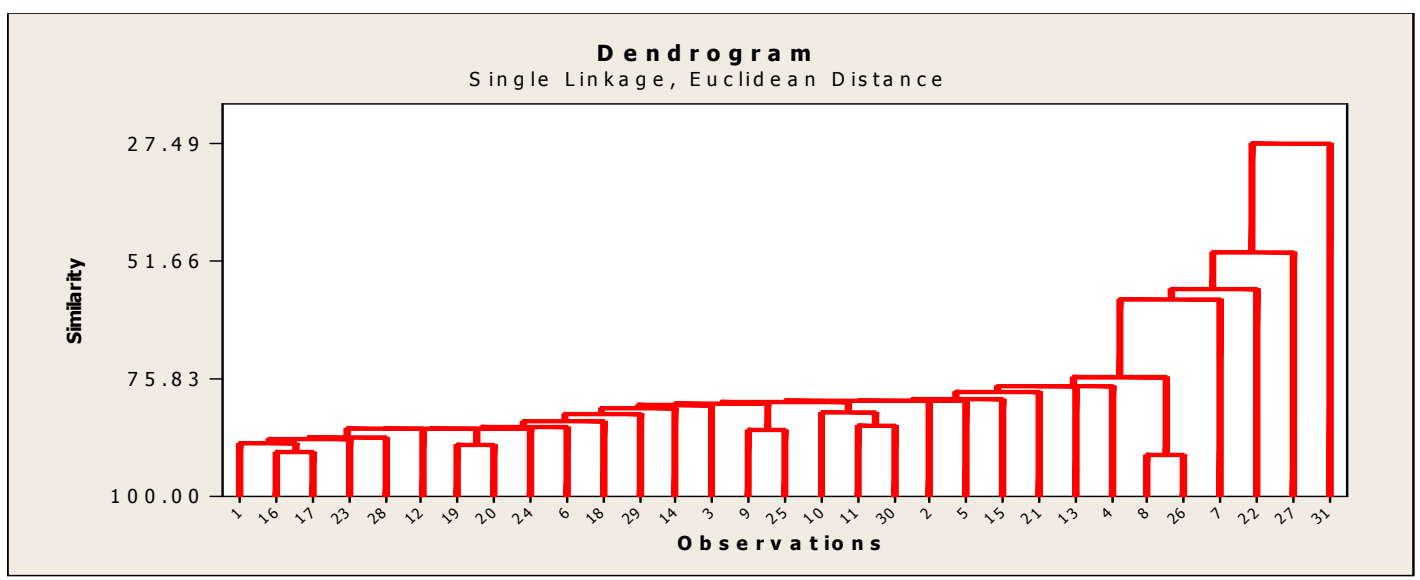

Fig.-4: Dendrogram of Cluster Analyze for Organ Chlorinated Pesticides in Analyzed Samples

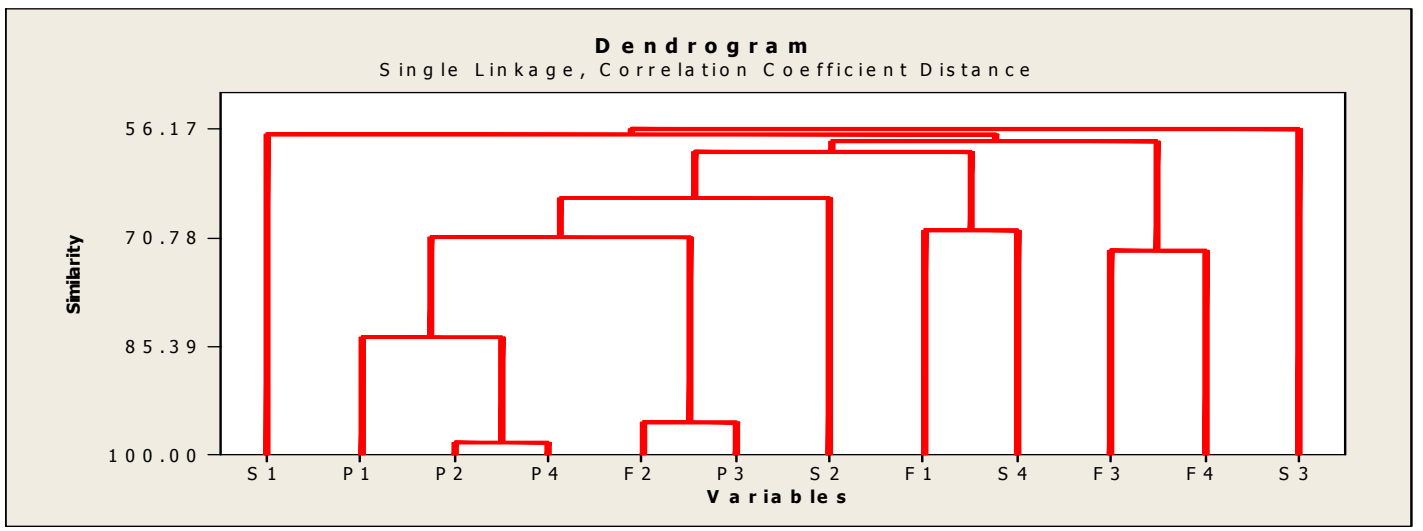

Fig.-5: Dendrogram of Cluster Analyze for Stations for Found Organ Chlorinated Pesticides in Analyzed Samples 
RASĀYAN J. Chem.

Vol. 12 | No. 3 |1540 - 1546| July - September | 2019

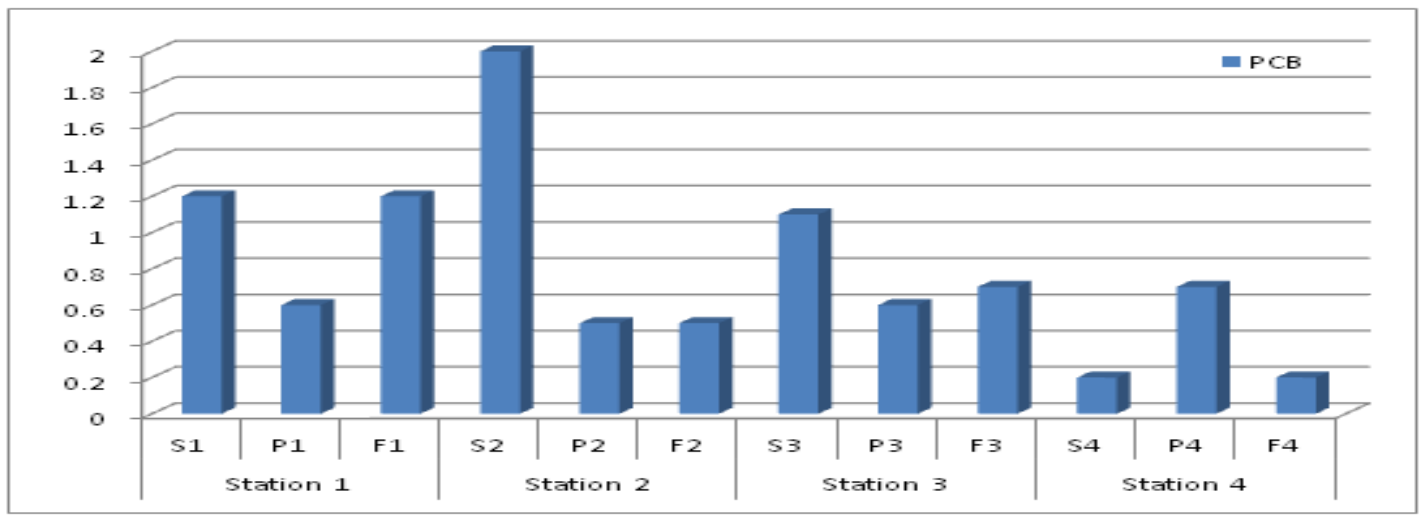

Fig.-6: Total of PCB in Analyzed in Soil, Plant and Tomato Fruit Samples

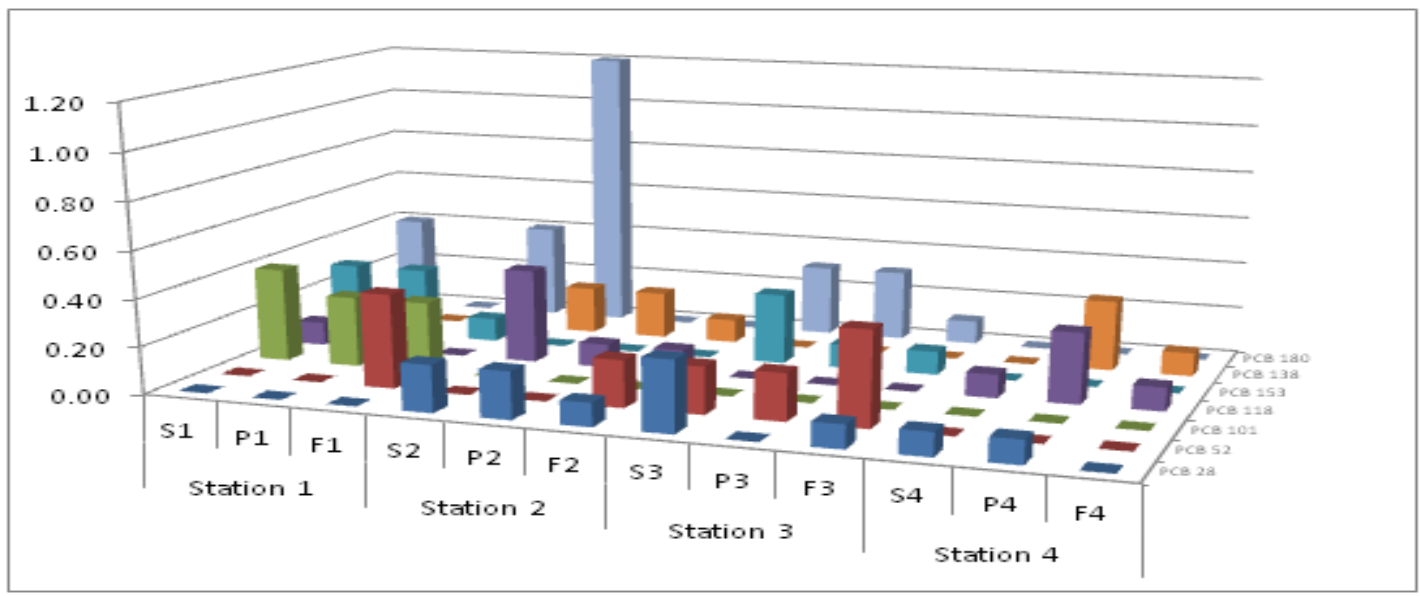

Fig.-7: Distribution of PCB in Analyzed in Soil, Plant and Tomato Fruit Samples

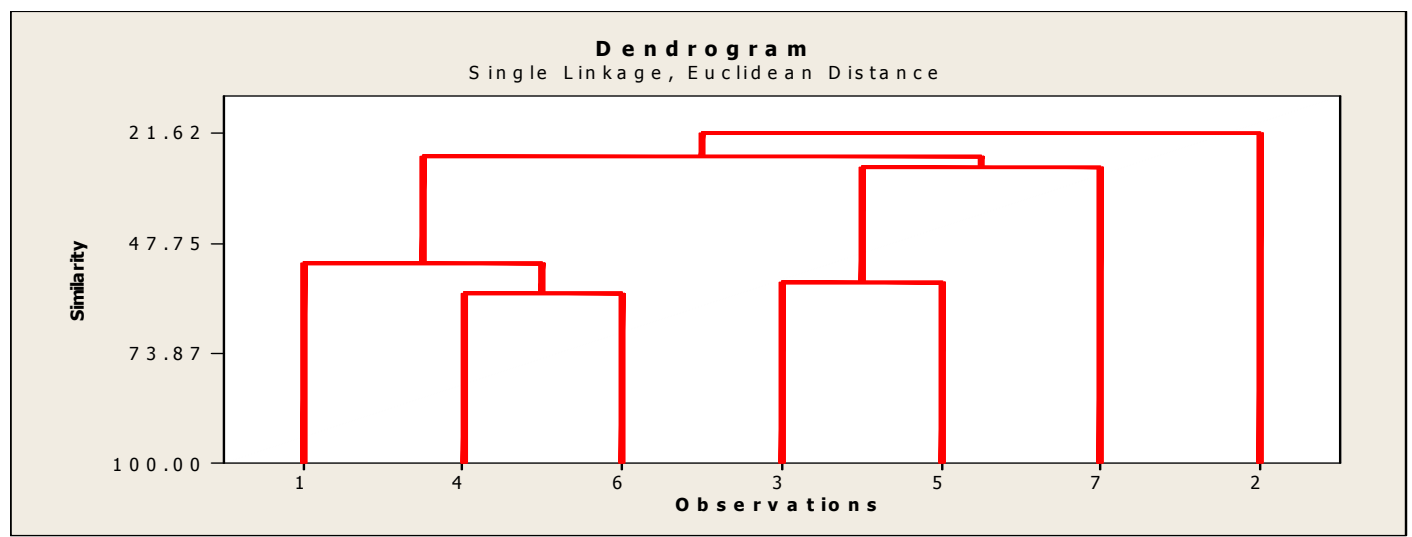

Fig.-8: Dendrogram of Cluster Analyze for PCBs in Analyzed Samples

Table-2: PCB Data in Soil, Plant and Tomato Fruit Samples (in ppm)

\begin{tabular}{c|c|c|c|c|c|c|c|c|c|c|c|c}
\hline & S1 & P1 & F1 & S2 & P2 & F2 & S3 & P3 & F3 & S4 & P4 & F4 \\
\hline PCB 28 & n.d & 0.00 & 0.00 & 0.20 & 0.20 & 0.20 & 0.30 & 0.00 & 0.10 & 0.10 & 0.20 & 0.00 \\
\hline PCB 52 & n.d & 0.00 & 0.40 & n.d & n.d & 0.20 & 0.20 & 0.20 & 0.40 & n.d & n.d & n.d \\
\hline $\begin{array}{c}\text { PCB } \\
101\end{array}$ & 0.40 & 0.30 & 0.30 & n.d & n.d & n.d & n.d & n.d & n.d & n.d & n.d & n.d \\
\hline $\begin{array}{c}\text { PCB } \\
118\end{array}$ & 0.10 & n.d & n.d & 0.30 & 0.10 & 0.30 & n.d & 0.00 & 0.00 & 0.10 & 0.30 & 0.10 \\
\hline $\begin{array}{c}\text { PCB } \\
153\end{array}$ & 0.30 & 0.30 & 0.10 & 0.00 & 0.00 & 0.00 & 0.30 & 0.10 & 0.10 & 0.00 & 0.00 & 0.00 \\
\hline
\end{tabular}


RASĀYAN J. Chem.

Vol. 12 | No. 3 |1540 - 1546| July - September | 2019

\begin{tabular}{c|c|c|c|c|c|c|c|c|c|c|c|r}
\hline $\begin{array}{c}\text { PCB } \\
138\end{array}$ & n.d & n.d & n.d & 0.20 & 0.20 & 0.10 & 0.00 & 0.00 & 0.00 & 0.00 & 0.30 & 0.10 \\
\hline $\begin{array}{c}\text { PCB } \\
180\end{array}$ & 0.40 & 0.00 & 0.30 & 1.20 & 0.00 & 0.00 & 0.30 & 0.30 & 0.10 & 0.00 & n.d & n.d \\
\hline
\end{tabular}

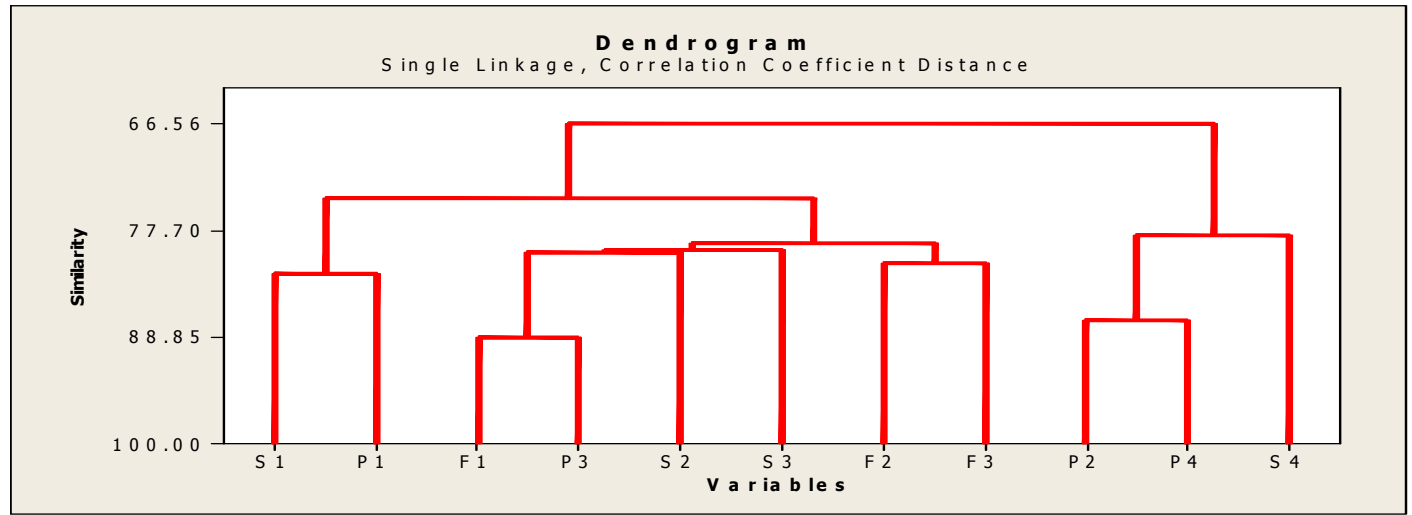

Fig.-9: Dendogram of Cluster Analyze for Stations for PCB Analyze

\section{CONCLUSION}

Determinations of organochlorinated pesticides and PCBs in soil, plant, and tomato fruit samples were realized in Kosovo Institute of Agricultural in Peja, Kosovo.

Organochlorinated pesticides and PCBs were determined based on EU protocols in soil and non-fatty food samples.

The higher levels of organochlorinated pesticides and PCB was founded in the samples which were taken in Qyshk. In the samples which were taken in Peja (village 4) we found the low level(below the MRL) of organochlorinated pesticides and PCB.

It was shown that higher levels were for Fruits $>$ Plant $>$ Soil. This could be because of the metabolism process from soil to plant and after that to fruit. Higher levels in fruit samples could be also because of pesticide treatments from agricultural purposes. Distribution of organ chlorinated pesticides was the same for all samples. The highest levels were for HCHs, Endrines, Endosulphanes and DDT metabolites. This could be connected to their geographical position, slope, soil geology, type of crops, water used for irrigation, etc.

Organochlorinated pesticide levels were lower than the acceptable concentration in soil and samples. PCBs were detected for all samples. The higher levels were found for soil samples. This could be because of pollution origin with PCB in these areas. Volatile PCBs were detected and also non-volatile one. This could be connected to their geographical position, slope, soil geology, water used for irrigation, PCB atmospheric deposition, etc.

\section{REFERENCES}

1. R. Lazar, A. Herrera, A. Arno, M. Pillar Consuelo, S. Barry, Agaric. Food Chem., 44, 2742(1996).

2. A. Nuro, K. Koci, E. Marku, Journal of Environmental Protection and Ecology, 8(3), 544(2007).

3. P. L. Penttila, K. Siivinen, Food Additives \& Contaminants: Part A, 13(6), 609(1996).

4. W.J.Rogan, A. Chen, Lancet., 366, 763(2005).

5. K. Skibniewska, S. Smoczynski, Żyw. Czlow. Metab., 27 (Supl), 279(2000).

6. M.Wilhelm, P. Schrey, J. Wittsiepe, B. Heinzow, Int. J. Hyg. Environ. Health, 204, 359(2002).

7. https://lovdata.no/static/SF/32018r1660e-01.pdf?timestamp $=1546310145000$ (Commission Implementing Regulation(EU) 2018/1660 of 7 November 2018 imposing special conditions governing the import of certain food of non-animal origin from certain third countries due to the risks of contamination with pesticides residues, amending Regulation (EC) No 669/2009 and repealing Implementing Regulation (EU) No 885/2014)

8. https://www.epa.gov/sites/production/files/2015-12/documents/8081b.pdf

[RJC-5301/2019] 